Emerson Tavares de Sousa ${ }^{1}$

Yago Tavares Pinheiro ${ }^{2}$

Jaiza Samara Macena de Araújo ${ }^{1}$

Jailton Macena de Araújo ${ }^{3}$

\title{
A QUESTÃO SOCIAL DA FLUORETAÇÃO DAS ÁGUAS E A EFETIVAÇÃO DO DIREITO À SAÚDE
}

The social issue of water fluoridation and the accomplishment of health rights

${ }^{1}$ Universidade Estadual de Campinas. Piracicaba/SP, Brasil.

${ }^{2}$ Faculdade Maurício de Nassau. João Pessoa/PB, Brasil.

3Universidade Federal da Paraíba. João Pessoa/PB, Brasil.

Correspondência: Emerson Tavares de Sousa. E-mail: etsemerson@yahoo.com.br.

Recebido: 19/04/2016. Revisado: 03/07/2017. Aprovado: 18/07/2017. 


\section{RESUMO}

A ampliação do conceito de saúde, historicamente acompanhado pelo contexto mundial de globalização da cultura de respeito e proteção dos direitos humanos, influenciou de forma significativa a criação e implementação de dispositivos jurídicos visando à garantia da seguridade social em todos os níveis como condição sine qua non para qualidade de vida e dignidade das pessoas. Nesse sentido, este trabalho tem como objetivo discutir as interfaces do direito que alicerçam a fluoretação das águas em território nacional como mecanismo básico essencial para a promoção de saúde bucal integral, universal e plena.

\section{Palavras-Chave}

Direito à Saúde; Direitos Humanos; Fluoretação; Saúde Bucal; Saúde Pública.

\section{ABSTRACT}

The expansion of the concept of health, historically accompanied by the universalization of the culture of respect and protection to human rights in a global context, has significantly influenced the creation and implementation of legal provisions that guarantee social security at all levels as a condition sine qua non for the quality of life and dignity of the individuals. Therefore, the objective of this study is to discuss the interfaces of the law, which underpin water fluoridation in the country as an essential, basic mechanism for promoting integral, universal and comprehensive oral health.

\section{Keywords}

Human Rights; Fluoridation; Oral Health; Public Health; Right to Health. 


\section{Introdução}

A ampliação do conceito de saúde, pautada na busca por um olhar diferenciado sobre a saúde da população e à luz das recomendações normativas internacionais e nacionais, torna-se necessária frente aos apelos que emergem das mais variadas realidades sociais. Nesse sentido, decisões públicas devem ser tomadas considerando-se ações interdisciplinares, multiprofissionais e intersetoriais, e articulando-se os diferentes determinantes da saúde às evidências estruturais, culturais e ambientais, com o objetivo de garantir efetividade e abrangência universal ${ }^{1}{ }^{2}$. Portanto, trata-se de estabelecer um padrão epidemiológico e de acesso aos serviços de saúde que possibilite a adequação da realidade das políticas públicas implementadas pelo Estado às reais necessidades sociais.

Como base metodológica, este trabalho alicerça-se no método de abordagem hipotético-dedutiva, alinhando as discussões sobre saúde pública e a fluoretação das águas ao amplo espectro constitucional de promoção e proteção do direito humano à saúde integral, igualitária e universal, como corolário da dignidade da pessoa humana e parte essencial do exercício dos direitos humanos. Manejou-se, para tanto, o método de procedimento monográfico, fundamentando a pesquisa sobre o arcabouço metajurídico que reconhece a interdisciplinaridade do direito com as ciências da saúde, de modo a amplificar o acesso aos mecanismos de saúde como parte de uma política pública de cidadania e de inclusão social.

No que se refere à técnica de pesquisa, parte-se essencialmente da pesquisa documental direta, com a análise da legislação nacional e internacional de proteção ao direito humano à saúde, como suporte para a exigência de atuação estatal na política pública de fluoretação, além do manejo da documentação indireta e da pesquisa bibliográfica. Partindo dessa constatação, o reconhecimento epistemológico do direito à saúde emerge como uma interface que garante proteção à pessoa humana e possibilita a concretização de direitos antes relegados a um plano secundário.

Nesse contexto, a saúde bucal busca na experiência de alteridade contrapor os efeitos de sua semântica fragmentada, direcionando-se para uma prática holística e humanizada. Essa modernização está diretamente relacionada e influenciada pelas correntes que surgiram ou se firmaram com o estabelecimento do Sistema Único de Saúde (SUS) e, anos depois, da Política Nacional de Saúde Bucal. Entretanto, apesar das crescentes melhorias na saúde bucal dos brasileiros, a doença denominada como cárie ainda representa um dos principais agravos em saúde pública, afetando de modo desigual a população.

\footnotetext{
${ }^{1}$ REIS, Joaquim. Modelo metateórico da psicologia da saúde para o século XXI: interação ou integração biopsicossocial? Revista Análise Psicológica, Lisboa, v. 3, n. 17, p. 415-433, set. 1999. Disponível em: <http://www.scielo.mec.pt/pdf/aps/v17n3/v17n3a02.pdf>.

${ }^{2}$ MEDEIROS, Patrícia Flores; BERNARDES, Anita Guazelli; GUARESCHI, Neuza. O conceito de saúde e suas implicações nas práticas psicológicas. Psicologia: teoria e pesquisa, Brasília, v. 21, n. 3, p. 263-269, set./dez. 2005. Disponível em: <http://www.scielo.br/pdf/ptp/v21n3/a02v21n3.pdf>. http://dx.doi.org/10.1590/ S0102-37722005000300002.
} 
No Brasil, entre 1980 e 2010, a redução nos valores do índice de dentes permanentes cariados, perdidos e obturados por criança aos 12 anos de idade (CPO-d) mostra uma consistente queda, a qual pode ser observada no país em sua totalidade ${ }^{3,4,5}$. Entretanto, dentro do panorama nacional, existem determinados grupos populacionais que experimentam diferentes graus de severidade da doença cárie dentária, como reflexo da desigualdade social, econômica e demografica. A redução dessa discrepância é majoritariamente um dos grandes focos da saúde bucal coletiva atualmente, sendo necessária a formulação de políticas de intervenção mais sólidas e efetivas em nível universal e contextual.

Em geral, os principais meios utilizados nas estratégias populacionais para prevenir a cárie dentária são os fluoretos veiculados no creme dental e na água de abastecimento público ${ }^{6}$, este último sendo o meio mais universal e democrático de acesso. Estudos evidenciam a menor prevalência de cárie em localidades com água fluoretada quando comparadas a regiões não fluoretadas ${ }^{7,8}$. Portanto, políticas públicas devem garantir a implementação, ampliação e continuidade do acesso ao tratamento da água e a sua fluoretação ${ }^{9}$. Dessa forma, julga-se oportuno remeter a discussão sobre a atuação do poder público na questão social da fluoretação das águas e os reflexos dessa atuação na efetivação do direito coletivo à saúde.

\section{Aspectos gerais acerca do direito à saúde}

O direito à saúde está inserido nos chamados direitos sociais: direitos humanos classificados como de segunda dimensão (direitos sociais, econômicos e culturais) que, tais como o direito ao trabalho, à educação, ao lazer, à greve, dentre

\footnotetext{
3BRASIL. Ministério da Saúde. Levantamento epidemiológico em saúde bucal: cárie dental. Brasília-DF: Ministério da Saúde, 1996.

${ }^{4}$ BRASIL. Ministério da Saúde. Secretaria de Atenção à Saúde. Departamento de Atenção Básica. Coordenação Nacional de Saúde Bucal. Projeto SB Brasil 2003 - Condições de saúde bucal da população brasileira 2002-2003: resultados principais. Brasília-DF: Ministério da Saúde, 2004. Disponível em: <http://bvsms. saude.gov.br/bvs/publicacoes/condicoes_saude_bucal.pdf >.

${ }^{5}$ BRASIL. Ministério da Saúde. Secretaria de Atenção à Saúde. Departamento de Atenção Básica. Secretaria de Vigilância em Saúde. Projeto SB Brasil 2010 - Pesquisa Nacional de saúde bucal: resultados principais. Brasília-DF: Ministério da Saúde, 2012. Disponível em: <http://bvsms.saude.gov.br/bvs/publicacoes/pesquisa_ nacional_saude_bucal.pdf>.

${ }^{6}$ NEWBRUN, E. What we know and do not know about fluoride. Journal Public Health Dent, California, v. 70, n. 3, p. 227-233, 2010. 10.1111/j.1752-7325.2010.00171.x.

${ }^{7}$ FRANZOLIN, Solange de Oliveira Braga et al. Epidemiology of fluorosis and dental caries according to different types of water supplies. Ciência e Saúde Coletiva, Rio de Janeiro, v. 15, n. 1, p. 1841-1847, Jun. 2010. Disponível em: <http://www.scielo.br/pdf/csc/v15s1/097.pdf>. http://dx.doi.org/10.1590/S1413-81232010000700097. ${ }^{8}$ CARVALHO, Raquel Baroni de. et al. Influência de diferentes concentrações de flúor na água em indicadores epidemiológicos de saúde/doença bucal. Ciência e Saúde Coletiva, Rio de Janeiro, v. 16, n. 8, p. 35093518, ago. 2011. Disponível em: <http://www.scielo.br/pdf/csc/v16n8/a19v16n8.pdf>. http://dx.doi. org/10.1590/S1413-81232011000900019.

${ }^{9}$ RAMIRES, Irene; BUZALAF, Maria Afonso Rabelo. A fluoretação da água de abastecimento público e seus benefícios no controle da cárie dentária - cinqüenta anos no Brasil. Ciência e Saúde Coletiva, Rio de Janeiro, v. 12, n. 4, p.1057-1065, jul./ago. 2007. Disponível em: <http://www.scielo.br/pdf/csc/v12n4/24. pdf>. http://dx.doi.org/10.1590/S1413-81232007000400027.
} 
outros, exigem uma atuação estatal para seu exercício. Os meios que proporcionam o exercício pleno da saúde devem ser ofertados pelo Estado, em decorrência da obrigação constitucional de promoção deste direito, expressa no artigo 196 da Constituição Federal de $1988(\mathrm{CF} / 1988)^{10}$ :

Art. 196. A saúde é direito de todos e dever do Estado, garantido mediante políticas sociais e econômicas que visem à redução do risco de doença e de outros agravos e ao acesso universal e igualitário às ações e serviços para sua promoção, proteção e recuperação.

O direito à saúde também deve ser efetivado por meio da garantia da dignidade da pessoa humana, princípio fundamental tutelado e declarado na Carta Magna:

Art. $1^{\circ}$. A República Federativa do Brasil, formada pela união indissolúvel dos Estados e Municípios e do Distrito Federal, constitui-se em Estado Democrático de Direito e tem como fundamentos: I - a soberania; II - a cidadania; III - a dignidade da pessoa humana; IV - os valores sociais do trabalho e da livre iniciativa; V - o pluralismo político. (Destaques nossos.)

No mesmo sentido, o direito à saúde como corolário da dignidade da pessoa humana é afirmado no artigo $6^{\circ}$ da CF/1988:

Art. $6^{\circ}$. São direitos sociais: a educação, a saúde, a alimentação, o trabalho, a moradia, o lazer, a segurança, a previdência social, a proteção à maternidade e à infância, a assistência aos desamparados, na forma desta Constituição. (Destaques nossos.)

Para Guerra e Emerique ${ }^{11}$, o princípio de dignidade da pessoa humana, enquanto princípio fundamental da república, "impõe um dever de abstenção e de condutas positivas tendentes a efetivar e proteger a pessoa humana", respeitando-se valores como autonomia, liberdade, integridade física e moral.

Ao vislumbrar a saúde como consentânea à dignidade, a Organização Mundial da Saúde ${ }^{12}$ (OMS) reconhece que a saúde abrange uma concepção ampla, expressa na compreensão de um estado de completo bem-estar físico, mental e social e não apenas na ausência de doença ou enfermidade. Então, usufruir o direito à saúde em sua plenitude é gozar do melhor estado de saúde que é possível atingir

\footnotetext{
${ }^{10}$ BRASIL. Constituição da República Federativa do Brasil de 1988. Disponível em: <http://www.planalto.gov. br/ccivil_03/constituicao/constituicaocompilado.htm>. Acesso em: 02 fev. 2018.

${ }^{11}$ GUERRA, Sidney; EMERIQUE, Lilian Márcia Balmant. O princípio da dignidade da pessoa humana e o mínimo existencial. Revista da Faculdade de Direito de Campos, Campos dos Goytacazes-RJ, v. 7, n. 9, p. 386, dez. 2006. Disponível em: <http://fdc.br/Arquivos/Mestrado/Revistas/Revista09/Artigos/Sidney.pdf>.

${ }^{12}$ ORGANIZAÇÃO MUNDIAL DA SAÚDE - OMS. Construção da Organização Mundial da Saúde. Documento Básico. Genebra: OMS, 1946.
} 
e se constitui um dos direitos fundamentais de todo ser humano, sem distinção de raça, religião, credo político, condição econômica ou social.

Desse modo, a saúde de todos é instrumento essencial para se conseguir a paz e a segurança ${ }^{13}$. Diante disso, são elementos básicos do conceito de saúde prelecionado pela OMS o bem-estar e a qualidade de vida. Elementos estes que também são considerados no conceito estabelecido pela Lei n. 8.080/1990 (Lei Orgânica da Saúde $)^{14}$, nos seguintes termos:

Art. $2^{\circ}$. A saúde é um direito fundamental do ser humano, devendo o Estado prover as condições indispensáveis ao seu pleno exercício.

[...]

Art. $3^{\circ}$. A saúde tem como fatores determinantes e condicionantes, entre outros, a alimentação, a moradia, o saneamento básico, o meio ambiente, o trabalho, a renda, a educação, o transporte, $o$ lazer e o acesso aos bens e serviços essenciais; os níveis de saúde da população expressam a organização social e econômica do País.

Parágrafo único. Dizem respeito também à saúde as ações que, por força do disposto no artigo anterior, se destinam a garantir às pessoas e à coletividade condições de bem-estar físico, mental e social.

Nesse contexto, reconhece-se a necessidade de promover o bem-estar e a saúde bucal às pessoas, independentemente de condição social, pautada na necessidade imperiosa de o poder público implementar ações que tenham como objetivo garantir a realização do tratamento e, principalmente, de prevenção de enfermidades.

Essa visão de saúde, garantida mediante dispositivos normativos de aplicação imediata (art. $5^{\circ}, \S 1^{\circ}, \mathrm{CF} / 1988$ ) e pétrea (art. 60, $\$ 4^{\circ}, 4, \mathrm{CF} / 1988$ ), deve ganhar uma dimensão ampliada a fim de reconhecer as peculiaridades culturais e monitorar as desigualdades sociais, no sentindo de efetivar práticas em saúde. Essa é uma importante tarefa na saúde pública, comumente identificada, na expressão de Antunes e Narvai ${ }^{15}$, como "vigilância em saúde". Dessa forma, as ações em saúde devem ter caráter multidisciplinar e multissetorial, com integração aos demais setores - incluindo defesa civil, educação, cultura, esportes e infraestrutura -, almejando, assim, desenvolvimento humano, qualidade de vida e justiça social.

\footnotetext{
${ }^{13}$ REZENDE, Nanci Figueirôa. A amplitude da expressão saúde no marco normativo brasileiro. In: BLIACHIERIENE, Ana Carla; SANTOS, José Sebastião (Orgs.). Direito à vida e à saúde: impactos orçamentário e judicial. São Paulo: Atlas, 2010.

${ }^{14}$ BRASIL. Lei n. 8.080, de 19 de setembro de 1990. Dispõe sobre as condições para a promoção, proteção e recuperação da saúde, a organização e o funcionamento dos serviços correspondentes e dá outras providências. Disponível em: <http://www.planalto.gov.br/ccivil_03/leis/l8080.htm>. Acesso em: 02 fev. 2018.

${ }^{15}$ ANTUNES, José Leopoldo Ferreira; NARVAI, Paulo Capel. Políticas de saúde bucal no Brasil e seu impacto sobre as desigualdades em saúde. Revista de Saúde Pública, São Paulo, v. 44, n. 2, p.360-365, 2010. Disponível em: <http:// www.scielo.br/pdf/rsp/v44n2/en_C01239.pdf>. http://dx.doi.org/10.1590/S0034-89102010005000002.
} 
É nesse sentido que se identifica a integridade da saúde humana, essencialmente a saúde bucal, como parâmetro de bem-estar e qualidade de vida. Nessa medida, mecanismos e promoção da saúde bucal devem ser vislumbrados como ferramentas aptas a tornar plena a dignidade da pessoa humana, especialmente reconhecida como parte do exercício dos direitos humanos e que exige, por sua própria natureza de direito social, a atuação estatal. Portanto, a fluoretação das águas, como será explicitado, funciona como instrumento de realização da saúde bucal dos sujeitos mais carentes e como meio de promoção da dignidade humana.

\section{A fluoretação das águas como medida preventiva de saúde coletiva}

A fluoretação de águas, como tecnologia de saúde, teve início no Estado de Michigan, nos Estados Unidos, em 1945. Naquele país, a fluoretação foi considerada pelos Centros de Controle e Prevenção de Doenças como uma das dez mais importantes conquistas da saúde pública no século XX. No Brasil, a primeira experiência ocorreu oito anos depois, no Município de Baixo Guandu, no Espírito Santo ${ }^{16,17}$.

Em 1974, graças ao interesse internacional, à globalização da pesquisa em fluoretação das águas e às experiências regionais exitosas, o governo de Ernesto Geisel tornou obrigatória a fluoretação das águas no Brasil pela Lei n. 6.050/1974 ${ }^{18}$, regulamentada pelo Decreto n. $76.872 / 1976^{19}$, sendo este um marco para saúde pública brasileira. Atualmente, a fluoretação das águas é uma medida recomendada por mais de 150 organizações científicas e de saúde, incluindo Federação Dentária Internacional, Associação Internacional de Pesquisa Odontológica, OMS e Organização Pan-Americana da Saúde (OPAS) ${ }^{20,21}$.

A partir do reconhecimento mundial da fluoretação como mecanismo de prevenção da cárie dentária e de promoção da saúde bucal, o Estado brasileiro normatizou a adição dos sais de fluoreto para o abastecimento de água destinada ao consumo humano na Lei n. 6.050/1974, nos seguintes termos:

\footnotetext{
${ }^{16}$ MÁRIO JÚNIOR, Rubens José; NARVAL, Paulo Capel. Aspectos históricos e perspectivas da fluoretação de águas de abastecimento público no Estado de São Paulo. Boletim Epidemiológico Paulista, São Paulo, v. 8, n. 9, p. 24-29, 2001. Disponível em: <http://saudepublica.bvs.br/pesquisa/resource/pt/ses-27994>.

${ }^{17}$ VIEGAS, AR. Cárie dental: prevenção e tratamento em odontologia sanitária. Arquivos da Faculdade de Higiene e Saúde Pública da USP, São Paulo, v. 29, n. 102, p. 189-206, 1964.

${ }^{18}$ BRASIL. Lei n. 6.050, de 24 de maio de 1974. Dispõe sobre a fluoretação da água em sistemas de abastecimento quando existir estação de tratamento. Disponível em: <http://www.planalto.gov.br/ ccivil_03/leis/L6050.htm>. Acesso em: 02 fev. 2018.

${ }^{19}$ BRASIL. Decreto n. 76.872, de 22 de dezembro de 1975. Regulamenta a Lei n. 6.050, de 24 de maio de 1974, que dispõe sobre a fluoretação da água em sistemas públicos de abastecimento. Disponível em: <http://www.planalto.gov.br/ccivil_03/decreto/antigos/d76872.htm>. Acesso em: 02 fev. 2018.

${ }^{20}$ BRASIL. Ministério da Saúde. Secretaria de Politicas de Saúde. Área Técnica de Saúde Bucal. Parecer técnico de 24 de agosto de 1999 - Comitê Técnico-Científico de Saúde Bucal. Fluoretação da água de consumo público no Brasil. Brasília-DF: Ministério da Saúde, 1999.

${ }^{21}$ MÁRIO JÚNIOR, Rubens José; NARVAL, Paulo Capel. op. cit., p. 24-29.
} 
Art. $1^{\circ}$. Os projetos destinados à construção ou à ampliação de sistemas públicos de abastecimento de água, onde haja estação de tratamento, devem incluir previsões e planos relativos à fluoretação da água, de acordo com os requisitos e para os fins estabelecidos no regulamento desta Lei.

Após a determinação legal da fluoretação da água para o consumo humano, o Ministério da Saúde expediu a Portaria n. 635/Bsb/1975 22 , aprovando as normas e os padrões para a fluoretação da água dos sistemas públicos de abastecimento destinada ao consumo humano. A portaria descreve conceitos essenciais acerca da fluoretação, métodos e quantitativos para que o procedimento seja realizado em benefício da saúde bucal, além de estabelecer requisitos mínimos aos quais os sistemas públicos de abastecimento de água fluoretada deverão obedecer ${ }^{23}$. Os padrões de potabilidade e qualidade da água para consumo humano são reforçados e reavaliados de forma contínua, sendo a especificação mais recente e já em revisão a Portaria n. 2.914/2011 ${ }^{24}$, que recomenda que a água contenha uma concentração de até 1,5 ppm de fluoreto (logicamente, esse tipo de parâmetro deve ser avaliado de acordo com as peculiaridades regionais, climáticas e sazonais).

A fluoretação é cientificamente comprovada como eficaz na prevenção da cárie dentária, sendo socialmente justa, de abrangência coletiva e com potencial de melhorar a saúde bucal da população ${ }^{25,26}$. Mostra, ainda, ser uma medida de expressivo impacto em realidades menos favorecidas, onde o contexto da cárie dentária torna persistente o quadro de apartheid social, caracterizado pelas precárias condições de existência a que é submetida parte da população ${ }^{27}$. Observa-se que, ao longo dos 40 anos de obrigatoriedade, apenas 3.351 (60,6\%) municípios efetuaram esse tipo de programa, a maioria concentrada nas regiões Sul e Sudeste ${ }^{28}$.

\footnotetext{
${ }^{22}$ BRASIL. Ministério da Saúde. Portaria n. 635/Bsb, de 26 de dezembro de 1975. Aprova normas e padrões sobre a fluoretação da água de sistemas públicos de abastecimento. Disponível em: <https://central3. to.gov.br/arquivo/349893/>. Acesso em: 02 fev. 2018.

${ }^{23}$ Id. Ibid.

${ }^{24}$ BRASIL. Ministério da Saúde. Portaria n. 2.914, de 12 de dezembro de 2011. Dispõe sobre os procedimentos de controle e de vigilância da qualidade da água para consumo humano e seu padrão de potabilidade. Disponível em: <http://bvsms.saude.gov.br/bvs/saudelegis/gm/2011/prt2914_12_12_2011.html>. Acesso em: 02 fev. 2018.

${ }^{25}$ BRASIL. Ministério da Saúde. Secretaria de Atenção à Saúde. Departamento de Atenção Básica. Coordenação de Saúde Bucal. Diretrizes da Política Nacional de Saúde Bucal. Brasília-DF: Ministério da Saúde, 2004. Disponível em: <http://189.28.128.100/dab/docs/publicacoes/geral/diretrizes_da_ politica_nacional_de_saude_bucal.pdf>. Acesso em: 02 fev. 2018.

${ }^{26} \mathrm{KUMAR}, \mathrm{JV}$. Is water fluoridation still necessary? Advances in Dental Research, New York, v. 20, n. 1, p. 8-12, Jul. 2008. 10.1177/154407370802000103.

${ }^{27}$ BUARQUE, Cristovam. A revolução nas prioridades: da modernidade técnica à modernidade ética. São Paulo: Paz e Terra, 1994. p. 287.

${ }^{28}$ BRASIL. Instituto Brasileiro de Geografia e Estatística - IBGE. Diretoria de Pesquisas Coordenação de População e Indicadores Sociais. Pesquisa Nacional de Saneamento Básico. Brasília-DF: Instituto Brasileiro de Geografia e Estatística - IBGE, 2008. Disponível em: <https://ww2.ibge.gov.br/home/presidencia/noticias/imprensa/ ppts/0000000105.pdf>. Acesso em: 02 fev. 2018.
} 
Nessa seara, a desigualdade social inerente ao próprio sistema capitalista é entendida como um fenômeno socioeconômico que influencia a saúde humana, sendo os efeitos deletérios maiores naquelas sociedades com algum grau de iniquidade social ${ }^{29}$. Segundo Whitehead e Dahlgren ${ }^{30}$, a iniquidade seria aquela desigualdade injusta, indesejável e evitável que se funda no caráter essencial da diferença. A iniquidade pressupõe exclusão, que é um fenômeno social e cultural, um fenômeno de civilização ${ }^{31}$.

Em saúde, quando se fala em iniquidade, emergem questões de acesso a serviços como educação de qualidade, programas de promoção e prevenção, saneamento básico, vigilância e segurança, entre outros, criando situações complexas que afetam diversos aspectos da vida humana. A essa evidência, fica claro o compromisso social de tornar legítimos os anseios das pessoas que não têm meios econômicos de promoverem tais serviços por suas próprias expensas - inclusive realizar todas as ações que permitam a prevenção da saúde bucal, como meio de lhes garantir a integralidade da saúde e, consentaneamente, sua dignidade ${ }^{32}$.

É nesse sentido que se deve ponderar que a pessoa humana e sua dignidade devem ser colocadas no centro do processo de desenvolvimento, como já ordena o texto constitucional brasileiro, onde elas se encontram no eixo de todos os direitos fundamentais. Para tal, torna-se imprescindível que se tenha em conta que os direitos sociais, como o direito à saúde, sejam realizados em decorrência de sua imprescindibilidade à justiça e à solidariedade. Nesse quadro, o desenvolvimento de cada cidadão - em especial daqueles mais vulneráveis social e economicamente - está “[...] inexoravelmente ligado ao desenvolvimento de todos os demais. É a essa compreensão que se liga à igualdade como caminho da liberdade em todos os seus aspectos" 33 .

Por essa razão, a fluoretação das águas - enquanto mecanismo reconhecidamente eficaz para a saúde bucal - deve ser garantida pelo Estado a todas as pessoas, em decorrência da determinação do artigo $2^{\circ}$, parágrafo $1^{\circ}$, da Lei n. 8.080/1990:

\footnotetext{
${ }^{29}$ FERREIRA, Maria Angela Fernandes; LATORRE, Maria do Rosário Dias de Oliveira. Desigualdade social e os estudos epidemiológicos: uma reflexão. Ciência e Saúde Coletiva, Rio de Janeiro, v. 17, n. 9, p. 25232531, set. 2012. Disponível em: <http://www.scielo.br/pdf/csc/v17n9/a32v17n9.pdf>. http://dx.doi. org/10.1590/S1413-81232012000900032.

${ }^{30}$ WHITEHEAD, Margaret; DAHLGRE, Göran. The concept and principles of equity and health: Levelling up Part I. Copenhagen: Pan American Health Organization (CID/HSP/PAHO), 1991.

${ }^{31}$ SANTOS, Boaventura de Sousa. A construção multicultural da igualdade e da diferença. [Publicação Seriada do Centro de Estudos Sociais]. Disponível em: <http://www.ces.uc.pt/publicacoes/oficina/135/135.pdf>. Acesso em: 03 abr. 2015.

${ }^{32}$ BUSS, Paulo M; PELLEGRINI FILHO, Alberto. Iniquidades em saúde no Brasil, nossa mais grave doença: comentários sobre o documento de referência e os trabalhos da Comissão Nacional sobre Determinantes Sociais da Saúde. Caderno de Saúde Pública, Rio de Janeiro, v. 22, n. 9, p. 2005-2008, set. 2006. Disponível em: <http://www.scielo.br/pdf/csp/v22n9/26.pdf>. http://dx.doi.org/10.1590/S0102-311X2006000900033.

${ }^{33}$ ARAÚJO, Jailton Macena. Políticas sociais e desenvolvimento: impactos da atuação estatal no desenvolvimento socioeconômico da população carente brasileira. Alemanha: Novas Edições Acadêmicas, 2013. p. 244.
} 
O dever do Estado de garantir a saúde consiste na formulação e execução de políticas econômicas e sociais que visem à redução de riscos de doenças e de outros agravos e no estabelecimento de condições que assegurem acesso universal e igualitário às ações e aos serviços para a sua promoção, proteção e recuperação (grifo nosso $)^{34}$. (Destaques nossos.)

A execução de mecanismos para tornar eficaz a fluoretação das águas, especialmente em regiões mais carentes, confere eficácia ao preceito normativo de assegurar acesso universal e igualitário aos serviços de proteção social, como decorrência lógica de um padrão de solidariedade e inclusão social.

\section{Questões sociais inerentes à efetivação da medida de fluoretação}

A doutrina democrática do Estado de Bem-Estar Social não se satisfaz com abstrações. Os direitos civis e políticos não devem ser expressão meramente formal da constituição e, por conseguinte, para que se realize a democracia, deve-se intentar sua concreção em todas as perspectivas sociais, com o propósito de garantir a emancipação da pessoa humana com a disponibilização de potencialidades básicas ${ }^{35}$, tudo isso como conditio sine qua non para a realização do desenvolvimento.

Nesse aspecto, o Estado social, apesar de sua alardeada crise, perquire o restabelecimento de princípios peculiares à justiça social, solidificando, por assim dizer, a proeminência do bem-estar geral do homem nas políticas inclusivas de saúde, dentre outros direitos sociais, além do devido respeito a direitos econômicos e culturais. Em apertada síntese, isso significa que esse tipo de Estado tem vistas à promoção da justiça, afora outros valores constitucionais que compelem a atuação estatal para o desenvolvimento. É esse o sentido do que afirma Rocha quando pontua:

[...] o perfil do Estado social reside no fato de ser um Estado intervencionista em duplo sentido: por um lado, intervém na ordem econômica, seja dirigindo e planejando o desenvolvimento econômico, seja fazendo inversões nos ramos da economia considerados estratégicos; por outro lado, intervém no social, onde dispensa prestações de bens e serviços e realiza outras atividades visando à elevação do nível de vida das populações reputadas mais carentes ${ }^{36}$.

Torna-se evidente, dessa forma, que a construção principiológica instituída pela ordem econômica brasileira na CF/1988 está ancorada primordialmente na justiça social e na solidariedade, princípios cujos efeitos práticos fundamentam as

\footnotetext{
${ }^{34}$ BRASIL. Lei n. 8.080, de 19 de setembro de 1990, cit.

${ }^{35}$ BONAVIDES, Paulo. Curso de direito constitucional. 16. ed. São Paulo: Malheiros Ed., 2005.

${ }^{36}$ ROCHA, José de Albuquerque. Estudos sobre o Poder Judiciário. São Paulo: Malheiros Ed., 1995. p. 129.
} 
ações estatais com o objetivo fundamental de promover o acesso universal, livre, justo e solidário aos direitos. Essa é a sociedade almejada e objetivada no artigo $3^{\circ}$ da CF/1988, que, pela compreensão desenvolvimentista e solidária do Estado, direciona a realização dos preceitos de justiça social.

Obviamente, os direitos socioeconômicos que afluem para a realização do direito ao desenvolvimento efetivam-se dentro dessa perspectiva de concretização plena que exige do Estado uma atuação comprometida, contínua e responsável, no sentido de sua integral realização. $\mathrm{O}$ grande desafio para a apreensão dos valores principiológicos, especialmente os relativos às estruturas públicas vigentes, é a efetiva contribuição dos princípios fundamentais do Estado brasileiro para que o desenvolvimento da sociedade se realize integralmente para todos. Nesse sentido, Canotilho considera que

[...] à medida que o Estado vai concretizando as suas responsabilidades no sentido de assegurar prestações existenciais aos cidadãos (é o fenômeno que a doutrina alemã designa por Daseinsvorsorge), resulta, de forma imediata, para os cidadãos: - o direito de igual acesso, obtenção e utilização de todas as instituições públicas criadas pelos poderes públicos (exemplos: igual acesso a instituições de ensino, igual acesso aos serviços de saúde, igual acesso à utilização das vias e transportes públicos); - o direito de igual quota-parte às prestações de saúde, às prestações escolares, às prestações de reforma e invalidez ${ }^{37}$.

Diante dessa compreensão de realização equânime dos preceitos constitucionais, a legalidade passa pela evolução de conteúdo, de modo a impor subordinação ao que é colocado na lei e também àquilo que é descrito na CF/1988 em seus princípios expressos ou implícitos. A lei é submetida à conformação constitucional e aos princípios que convergem para a promoção da pessoa humana em todos os seus aspectos. $\mathrm{E}$ a atuação estatal na promoção do acesso aos cidadãos, em especial aos mais vulneráveis, permite a inclusão social.

O acesso a direitos sociais como ao trabalho decente, à alimentação adequada, à moradia condigna e, em especial, à saúde pública de qualidade garante as condições mínimas para o exercício dos direitos humanos em sua totalidade, possibilitando o exercício pleno da cidadania ${ }^{38}$.

\footnotetext{
${ }^{37}$ CANOTILHO, José Joaquim Gomes. Direito constitucional e teoria da Constituição. 5. ed. Coimbra: Almedina, 2002. p. 541-542.

${ }^{38}$ ARAÚJO, Jailton Macena. Função emancipadora das políticas sociais do Estado brasileiro: conformação das ações assistenciais do programa bolsa família ao valor social do trabalho. 2016. 400f. Tese (Doutorado em Ciências Jurídicas). Programa de Pós-Graduação em Ciências Jurídicas, Universidade Federal da Paraíba, João Pessoa, 2016. p. 59.
} 
A Declaração Universal dos Direitos Humanos ${ }^{39}$, quando trata dos direitos econômicos e sociais, enuncia: "Toda pessoa tem direito a um nível de vida suficiente para assegurar a si e a sua família a saúde e o bem-estar". Por sua vez, a Declaração Internacional dos Direitos Econômicos, Sociais e Culturais, ratificada pelo Brasil em $1992^{40}$, em seu artigo 12 acrescenta:

Os Estados-Partes do presente Pacto reconhecem o direito de toda pessoa de desfrutar o mais elevado nível de saúde física e mental. As medidas que os Estados-Partes do presente Pacto deverão adotar, com o fim de assegurar o pleno exercício desse direito, incluirão as medidas que se façam necessárias para assegurar: [...] A prevenção e o tratamento das doenças epidêmicas, endêmicas, profissionais e outras, bem como a luta contra essas doenças [...].

Mencionadas determinações têm reflexo no ordenamento jurídico interno. Estabelece-se, no plano constitucional, o direito à fluoretação como reafirmação implícita e indireta do direito à saúde, previsto no artigo 196 da CF/1988. Dessa forma, a omissão do poder público na implementação da fluoretação reflete clara omissão ao direito à saúde, por negar a realização dos mecanismos preventivos básicos contra a cárie, impedindo a integralidade da saúde.

Quando se analisa a previsão constitucional do direito à saúde, como decorrente de uma atenção integral à saúde do cidadão que vise à redução do risco de doença ou da agudização de enfermidades, encontra-se uma generalização que força as três esferas de governo (federal, estadual e municipal) a articular medidas coletivas e individuais no sentido de assegurar esse direito, que deve ser garantido a todos.

Seguindo essa perspectiva, a Lei n. 8.080/1990, que criou o SUS, ratifica o artigo $196 \mathrm{da} C F / 1988$ e regulamenta princípios que devem ser seguidos para o pleno funcionamento do sistema, a saber: a universalidade, a integralidade e a equidade. Os princípios do SUS constituem-se em pilares da saúde pública no Brasil, devendo ser observados como base sobre a qual toda e qualquer política de saúde deve ser assentada. Todo esse aparato é parte da Política Nacional de Saúde Bucal (Brasil Sorridente), quando trata das ações de promoção e proteção da saúde bucal em âmbito coletivo.

Na perspectiva da efetivação da prática de fluoretação das águas, estudo de Bleicher et al. ${ }^{41}$ sobre a implementação da fluoretação no Estado do Ceará conclui

\footnotetext{
${ }^{39}$ ORGANIZAÇÃO DAS NAÇÕES UNIDAS - ONU. Declaração Universal dos Direitos Humanos. 1948. Disponível em: <http://www.onu.org.br/img/2014/09/DUDH.pdf>. Acesso em: 02 fev. 2018.

${ }^{40}$ BRASIL. Decreto n. 591, de 6 de julho de 1992. Atos Internacionais. Pacto Internacional sobre Direitos Econômicos, Sociais e Culturais. Promulgação. Disponível em: <http://www.planalto.gov.br/ccivil_03/ decreto/1990-1994/d0591.htm>. Acesso em: 02 fev. 2018.

${ }^{41}$ BLEICHER, Lana; FROTA, Francisco Horácio da Silva. Fluoretação da água: uma questão de política pública - o caso do Estado do Ceará. Ciência e saúde coletiva, Rio de Janeiro, v. 11, n. 1, p. 71-78, 2011. Disponível em: <http:// www.scielo.br/pdf/csc/v11n1/29450.pdf>. http://dx.doi.org/10.1590/S1413-81232006000100014.
} 
que, para a obtenção de patamares mais elevados de cobertura por água tratada, será necessária a retomada de uma política de incentivo mediante financiamento federal, com o impedimento da privatização do setor de saneamento, a inscrição da medida na pauta de reivindicações populares e a adoção, por parte das instituições que realizam o abastecimento de água, de uma cultura institucional que favoreça a fluoretação. Do ponto de vista prático, o estudo de $A b u-E l-H a j^{42}$ analisa as políticas de saúde dos governos e afirma que as medidas mais bem acolhidas são as que demonstram, mediante cálculos financeiros, a melhor relação custo-eficácia.

As políticas públicas de prevenção da saúde bucal apontam importantes resultados na integralidade da saúde, tornando-se instrumentos para a inclusão social - cuja proteção é fundada na ordem constitucional brasileira, por meio de medidas especiais para o alcance da isonomia não apenas formal, mas também, e sobretudo, material ou substantiva (que define e determina a igualdade de acesso aos meios de saúde entre todos os cidadãos). Por se expressar de forma tão genérica, abrangente e heterogênea, permite uma relativização que traz dificuldades de ordem filosófica, política, jurídica, social, econômica, cultural e técnico-científica no momento de sua realização. . O desafio de articular esses elementos e estabelecer os acordos necessários tem promovido, cada vez mais, o distanciamento entre o direito vigente na lei e o direito praticado ${ }^{43}$, ensejando uma crise de facticidade que impede a realização dos princípios constitucionais.

Atribui-se, por sua vez, a situação de não fluoretação dos reservatórios de água que servem ao abastecimento das populações nos municípios brasileiros a um problema naturalmente político, que deve ser enfrentado buscando-se a forma mais segura de garantir, proteger e evitar violação clara ao direito à saúde. Em termos práticos, seguindo o conceito de justiça social, a judicialização como medida para buscar a efetivação da fluoretação pode ser bem fundamentada no contexto brasileiro, exigindo-se, pois, que as determinações da portaria sejam postas em prática em razão de sua adequação ao direito à saúde. Nesse contexto, Bobbio ${ }^{44}$ afirma que "o problema fundamental em relação aos direitos do homem, hoje, não é tanto o de justificá-los, mas o de protegê-los. Trata-se de um problema não filosófico, mas político”.

Ventura et al. $^{45}$ afirmam que, no contexto democrático contemporâneo, a judicialização da saúde remete às reivindicações em prol da garantia e da promoção dos direitos de cidadania afirmados nas leis internacionais e nacionais, sendo um fenômeno que envolve aspectos políticos, sociais, éticos e sanitários que vão muito

\footnotetext{
${ }^{42}$ ABU-EL-HAJ, Jawdat. A mobilização do capital social no Brasil: o caso da reforma sanitária no Ceará. São Paulo: Annablume, 2000. p. 234.

${ }^{43}$ VENTURA, Miriam. et. al. Judicialização da saúde, acesso à justiça e a efetividade do direito à saúde. Physis: revista de saúde coletiva, Rio de Janeiro, v. 20, n. 1, p. 77-99, 2010. Disponível em: <http://www.scielo.br/ pdf/physis/v20n1/a06v20n1.pdf>. http://dx.doi.org/10.1590/S0103-73312010000100006.

${ }^{44}$ BOBBIO, Norberto. A era dos direitos. Rio de Janeiro: Elsevier, 2004. p. 16.

${ }^{45}$ Id. Ibid.
} 
além de seu componente jurídico e de gestão de serviços públicos - apesar desse termo ser bem polêmico, levando a discussões bastante complexas nos setores da saúde e do direito, especialmente quando se trata de demanda judicial individualizada. A judicialização em torno da realização dos direitos sociais apresenta-se como elemento primordial à efetivação da saúde integral do indivíduo.

A saber, a fluoretação é comprovada como método eficaz de redução das iniquidades em saúde bucal. Entretanto, a determinação da fluoretação da água abastecida para o consumo humano ainda é objeto de não cumprimento, o que se apresenta como violação direta aos direitos humanos e fundamentais.

\section{Considerações Finais}

A tutela estatal é direcionada à correção das situações históricas de desigualdade e violação, assim como à promoção da justiça social ${ }^{46}$. Portanto, as condições de efetivação da justiça social são dependentes da atuação positiva do Estado na ordem econômica e social, o que compreende as ações de saúde pública.

Não se pode olvidar de que a fluoretação é comprovadamente um método eficaz de redução das iniquidades em saúde bucal e deve ser pauta das políticas públicas estatais de promoção do bem-estar e da qualidade de vida da população. E, por sua vez, a não execução da fluoretação revela verdadeira omissão quanto à realização do direito à saúde, configurando verdadeira violação aos direitos humanos e à dignidade humana.

Em virtude da busca pela efetivação do Estado de Bem-Estar Social, impõe-se aos poderes públicos o dever de formular estratégias políticas de desenvolvimento socioeconômico com vistas à efetivação dos direitos sociais, de modo a garantir também a maior eficácia jurídica possível desses direitos fundamentais. Sendo assim, o mínimo de igualdade é necessário para a realização do desenvolvimento socioeconômico, político e cultural do povo, porquanto é fundamental a garantia do mínimo de direitos capazes de satisfazer as prerrogativas mínimas previstas no texto constitucional e, principalmente, nos instrumentos internacionais de proteção aos direitos humanos.

Tendo em vista as consequências que a cárie dentária pode causar em nível biológico e psicossocial é extremamente importante atentar para questões relativas à prevenção e promoção, principalmente quando se trata de um método que abrange a todos, independentemente de classe social, gênero e faixa etária. Entretanto, do ponto de vista da implementação do método, entende-se que muito se tem a enfrentar, fazendo emergir alguns questionamentos quanto a não efetivação da medida em todo o território nacional e quanto ao controle da medida já implantada.

\footnotetext{
${ }^{46}$ AVELAR, Matheus Rocha. Manual de direito constitucional. 5. ed. Curitiba: Juruá, 2009.
} 
A participação popular torna-se elemento primordial na reivindicação de melhores serviços de abastecimento de água, no reforço à cultura institucional de fluoretação das águas como meio primordial de prevenção da cárie e de promoção da saúde e como critério de maior eficácia social e econômica. Assim, a fluoretação das águas em regiões mais carentes confere eficácia à política pública de saúde, garantido acesso universal e igualitário aos serviços de proteção à saúde bucal.

Portanto, para que seja possível o patamar mínimo de saúde bucal com a fluoretação, deve ser garantida a ampliação da cobertura do tratamento de água, com a retomada da política de incentivo ao saneamento.

\section{Referências}

ABU-EL-HAJ, Jawdat. A mobilização do capital social no Brasil: o caso da reforma sanitária no Ceará. São Paulo: Annablume, 2000.

AMERICAN DENTAL ASSOCIATION - ADA. Fluoridation facts. Chicago: Illinois. Disponível em: <http://www.ada.org/ /media/ADA/Member\%20Center/FIles/fluoridation_ facts.ashx>. Acesso em: 03 abr. 2015.

ANTUNES, José Leopoldo Ferreira; NARVAI, Paulo Capel. Políticas de saúde bucal no Brasil e seu impacto sobre as desigualdades em saúde. Revista de Saúde Pública, São Paulo, v. 44, n. 2, p. 360-365, 2010. Disponível em: <http://www.scielo.br/pdf/rsp/v44n2/en_CO1239.pdf >. http://dx.doi.org/10.1590/S0034-89102010005000002.

ARAÚJO, Jailton Macena. Função emancipadora das políticas sociais do Estado brasileiro: conformação das ações assistenciais do programa bolsa família ao valor social do trabalho. 2016. 400f. Tese (Doutorado em Ciências Jurídicas). Programa de Pós-Graduação em Ciências Jurídicas, Universidade Federal da Paraíba, João Pessoa, 2016.

. Políticas sociais e desenvolvimento: impactos da atuação estatal no desenvolvimento socioeconômico da população carente brasileira. Alemanha: Novas Edições Acadêmicas, 2013.

AVELAR, Matheus Rocha. Manual de direito constitucional. 5. ed. Curitiba: Juruá, 2009.

BLEICHER, Lana; FROTA, Francisco Horácio da Silva. Fluoretação da água: uma questão de política pública - o caso do Estado do Ceará. Ciência e saúde coletiva, Rio de Janeiro, v. 11, n. 1, p. 71-78, 2011. Disponível em: <http://www.scielo.br/pdf/csc/v11n1/29450.pdf>. http://dx.doi.org/10.1590/S1413-81232006000100014.

BOBBIO, Norberto. A era dos direitos. Rio de Janeiro: Elsevier, 2004.

BONAVIDES, Paulo. Curso de direito constitucional. 16. ed. São Paulo: Malheiros Ed., 2005.

BRASIL. Ministério da Saúde. Levantamento epidemiológico em saúde bucal: cárie dental. Brasília-DF: Ministério da Saúde, 1996. 
BRASIL. Ministério da Saúde. Secretaria de Atenção à Saúde. Departamento de Atenção Básica. Coordenação Nacional de Saúde Bucal. Projeto SB Brasil 2003 - Condições de saúde bucal da população brasileira 2002-2003: resultados principais. Brasília-DF: Ministério da Saúde, 2004. Disponível em: <http://bvsms.saude.gov.br/bvs/publicacoes/ condicoes_saude_bucal.pdf $>$.

Ministério da Saúde. Secretaria de Atenção à Saúde. Departamento de Atenção Básica. Coordenação de Saúde Bucal. Diretrizes da Política Nacional de Saúde Bucal. Brasília-DF: Ministério da Saúde, 2004. Disponível em: <http://189.28.128.100/dab/docs/publicacoes/ geral/diretrizes_da_politica_nacional_de_saude_bucal.pdf $>$.

Ministério da Saúde. Secretaria de Atenção à Saúde. Departamento de Atenção Básica. Secretaria de Vigilância em Saúde. Projeto SB Brasil 2010 - Pesquisa Nacional de saúde bucal: resultados principais. Brasília-DF: Ministério da Saúde, 2012. Disponível em: $<$ http://bvsms. saude.gov.br/bvs/publicacoes/pesquisa_nacional_saude_bucal.pdf $>$.

Ministério da Saúde. Secretaria de Politicas de Saúde. Área Técnica de Saúde Bucal. Parecer técnico de 24 de agosto de 1999 - Comitê Técnico-Científico de Saúde Bucal. Fluoretação da água de consumo público no Brasil. Brasília-DF: Ministério da Saúde, 1999.

Instituto Brasileiro de Geografia e Estatística - IBGE. Diretoria de Pesquisas Coordenação de População e Indicadores Sociais. Pesquisa Nacional de Saneamento Básico. Brasília-DF: Instituto Brasileiro de Geografia e Estatística - IBGE, 2008. Disponível em: $<$ https://ww2.ibge.gov.br/home/presidencia/noticias/imprensa/ppts/0000000105.pdf>.

BUARQUE, Cristovam. A revolução nas prioridades: da modernidade técnica à modernidade ética. São Paulo: Paz e Terra, 1994.

BUSS, Paulo M; PELLEGRINI FILHO, Alberto. Iniquidades em saúde no Brasil, nossa mais grave doença: comentários sobre o documento de referência e os trabalhos da Comissão Nacional sobre Determinantes Sociais da Saúde. Caderno de Saúde Pública, Rio de Janeiro, v. 22, n. 9, p. 2005-2008, set. 2006. Disponível em: <http://www.scielo.br/pdf/csp/v22n9/26. pdf>. http://dx.doi.org/10.1590/S0102-311X2006000900033.

CANOTILHO, José Joaquim Gomes. Direito constitucional e teoria da Constituição. 5. ed. Coimbra: Almedina, 2002.

CARVALHO, Raquel Baroni de. et al. Influência de diferentes concentrações de flúor na água em indicadores epidemiológicos de saúde/doença bucal. Ciência e Saúde Coletiva, Rio de Janeiro, v. 16, n. 8, p. 3509-3518, ago. 2011. Disponível em: <http://www.scielo.br/pdf/csc/ v16n8/a19v16n8.pdf>. http://dx.doi.org/10.1590/S1413-81232011000900019.

CENTRO DE CONTROLE E PREVENÇÃO DE DOENÇAS (CDC). Achievements in Public Health, 1900-1999. Fluoridation of drinking water to prevent dental caries. Morbidity and Mortality Weekly Report, v. 48, n. 41, p. 933-940, Oct. 1999. Disponível em: <https://www. cdc.gov/mmwr/preview/mmwrhtml/mm4841a1.htm >. 
FERREIRA, Maria Angela Fernandes; LATORRE, Maria do Rosário Dias de Oliveira. Desigualdade social e os estudos epidemiológicos: uma reflexão. Ciência e Saúde Coletiva, Rio de Janeiro, v. 17, n. 9, p. 2523-2531, set. 2012. Disponível em: <http://www.scielo.br/pdf/ csc/v17n9/a32v17n9.pdf >. http://dx.doi.org/10.1590/S1413-81232012000900032.

FRANZOLIN, Solange de Oliveira Braga et al. Epidemiology of fluorosis and dental caries according to different types of water supplies. Ciência e Saúde Coletiva, Rio de Janeiro, v. 15, n. 1, p. 1841-1847, Jun. 2010. Disponível em: <http://www.scielo.br/pdf/csc/v15s1/097.pdf>. http://dx.doi.org/10.1590/S1413-81232010000700097.

GUERRA, Sidney; EMERIQUE, Lilian Márcia Balmant. O princípio da dignidade da pessoa humana e o mínimo existencial. Revista da Faculdade de Direito de Campos, Campos dos Goytacazes-RJ, v. 7, n. 9, p. 379-397, dez. 2006. Disponível em: <http:/fdc.br/Arquivos/ Mestrado/Revistas/Revista09/Artigos/Sidney.pdf>.

KUMAR, JV. Is water fluoridation still necessary? Advances in Dental Research, New York, v. 20, n. 1, p. 8-12, Jul. 2008. 10.1177/154407370802000103.

MÁRIO JÚNIOR, Rubens José; NARVAL, Paulo Capel. Aspectos históricos e perspectivas da fluoretação de águas de abastecimento público no Estado de São Paulo. Boletim Epidemiológico Paulista, São Paulo, v. 8, n. 9, p. 24-29, 2001. Disponível em: <http://saudepublica.bvs.br/ pesquisa/resource/pt/ses-27994>.

MEDEIROS, Patrícia Flores; BERNARDES, Anita Guazelli; GUARESCHI, Neuza. O conceito de saúde e suas implicações nas práticas psicológicas. Psicologia: teoria e pesquisa, Brasília, v. 21, n. 3, p. 263-269, set./dez. 2005. Disponível em: <http://www.scielo.br/pdf/ptp/v21n3/ a02v21n3.pdf>. http://dx.doi.org/10.1590/S0102-37722005000300002.

NEWBRUN, E. What we know and do not know about fluoride. Journal Public Health Dent, California, v. 70, n. 3, p. 227-233, 2010. 10.1111/j.1752-7325.2010.00171.x.

ORGANIZAÇÃO MUNDIAL DA SAÚDE - OMS. Construção da Organização Mundial da Saúde. Documento Básico. Genebra: OMS, 1946.

RAMIRES, Irene; BUZALAF, Maria Afonso Rabelo. A fluoretação da água de abastecimento público e seus benefícios no controle da cárie dentária - cinqüenta anos no Brasil. Ciência e Saúde Coletiva, Rio de Janeiro, v. 12, n. 4, p.1057-1065, jul./ago. 2007. Disponível em: <http:// www.scielo.br/pdf/csc/v12n4/24.pdf>. http://dx.doi.org/10.1590/S1413-81232007000400027.

REIS, Joaquim. Modelo metateórico da psicologia da saúde para o século XXI: interação ou integração biopsicossocial? Revista Análise Psicológica, Lisboa, v. 3, n. 17, p. 415-433, set. 1999. Disponível em: <http://www.scielo.mec.pt/pdf/aps/v17n3/v17n3a02.pdf>.

REZENDE, Nanci Figueirôa. A amplitude da expressão saúde no marco normativo brasileiro. In: BLIACHIERIENE, Ana Carla; SANTOS, José Sebastião (Orgs.). Direito à vida e à saúde: impactos orçamentário e judicial. São Paulo: Atlas, 2010.

ROCHA, José de Albuquerque. Estudos sobre o Poder Judiciário. São Paulo: Malheiros Ed., 1995. 
SANTOS, Boaventura de Sousa. A construção multicultural da igualdade e da diferença. [Publicação Seriada do Centro de Estudos Sociais]. Disponível em: <http://www.ces.uc.pt/ publicacoes/oficina/135/135.pdf>. Acesso em: 03 abr. 2015.

VENTURA, Miriam. et. al. Judicialização da saúde, acesso à justiça e a efetividade do direito à saúde. Physis: revista de saúde coletiva, Rio de Janeiro, v. 20, n. 1, p. 7799, 2010. Disponível em: <http://www.scielo.br/pdf/physis/v20n1/a06v20n1.pdf>. http://dx.doi.org/10.1590/S0103-73312010000100006.

VIEGAS, AR. Cárie dental: prevenção e tratamento em odontologia sanitária. Arquivos da Faculdade de Higiene e Saúde Pública da USP, São Paulo, v. 29, n. 102, p. 189-206, 1964.

WHITEHEAD, Margaret; DAHLGRE, Göran. The concept and principles of equity and health: Levelling up Part I. Copenhagen: Pan American Health Organization (CID/HSP/ PAHO), 1991.

Emerson Tavares de Sousa - Doutorando em Odontologia da Faculdade de Odontologia de Piracicaba da Universidade Estadual de Campinas; mestre em Odontologia com ênfase em Epidemiologia pela Universidade Federal da Paraíba (UFPB); especialista em Direitos Humanos pela Universidade Federal de Campina Grande; especialista em Saúde Pública pela Faculdade Integrada de Patos; graduado em Odontologia pela UFPB. Piracicaba/SP, Brasil. E-mail: etsemerson@yahoo.com.br.

Yago Tavares Pinheiro - Mestrando em Ciências da Reabilitação pela Faculdade de Ciências da Saúde do Trairí da Universidade Federal do Rio Grande do Norte; graduado em Fisioterapia pela Faculdade Maurício de Nassau. João Pessoa/PB, Brasil. E-mail: yagostavares5@gmail.com.

Jaiza Samara Macena de Araújo-Doutoranda em Odontologia pela Faculdade de Odontologia de Piracicaba da Universidade Estadual de Campinas; graduada em Odontologia pela Universidade Federal da Paraíba. Bolsista de Graduação Sanduíche na Griffith University (Austrália) pelo Programa Ciências sem Fronteiras. Piracicaba/SP, Brasil.E-mail: ja_samara@hotmail.com.

Jailton Macena de Araújo - Doutor em Ciências Jurídicas, área de concentração Direitos Humanos e Desenvolvimento, pela Universidade Federal da Paraíba (UFPB); mestre em Ciências Jurídicas, área de concentração em Direito Econômico, pela UFPB; graduado em Direito pela Universidade Federal de Campina Grande. Professor do Curso de Direito da UFPB. Advogado. João Pessoa/PB, Brasil.E-mail: jailtonma@gmail.com. 